\title{
TRADISI AURODAN DI UJUNG SELATAN GARUT JAWA BARAT
}

\author{
Saepurohman \\ UIN Sunan Gunung Djati Bandung \\ J1. A.H. Nasution 105 Cibiru Kota Bandung \\ Email: saepurohman1980@gmail.com
}

\begin{abstract}
Abstrak
Tujuan penulisan ini untuk memberi gambaran mengenai tradisi aurodan di Kampung Cikantrieun, Desa Wangunjaya, Kecamatan Banjarwangi Kabupaten Garut, Provinsi Jawa Barat. Hal ini dilatar belakangi bahwa Indonesia merupakan Negara kaya akan budaya dan tradisi, setiap daerah yang ada di Indonesia bisa dipastikan punya budaya dan tradisi masing-masing, dari sekian banyak budaya dan tradisi Indonesia ada yang terdokumentasikan ada yang tidak, sangat mungkin ada budaya dan tradisi suatu daerah terpencil yang belum di ketahui masyarakat luas, untuk itu penulis coba sampaikan suatu tradisi keagamaan yang berada di suatu daerah terpencil di bagian ujung selatan Garut tepatnya di Kampung Cikantrieun, Desa Wangunjaya, Kecamatan Banjarwangi Kabupaten Garut, Provinsi Jawa Barat. Tulisan berdasarkan wawancara dan observasi ini menguraikan bagaimana asal usul tradisi aurodan, tujuan masyarakat dalam melaksanakan kegiatan aurodan, manfaat aurodan, proses kegiatan aurodan dan bacaan-bacaan dalam aurodan serta dalil-dalilnya. Tradisi aurodan di Kampung Cikantrieun sudah ada sejak puluhan tahun silam, dalam perjalannya mengalami perubahan dan perkembangan, seiring dengan perubahan dan perkembangan pemikiran masyarakat yang ada di kampung Cikantrieun itu sendiri, terutama tokoh agama dan tokoh masyarakat.
\end{abstract}

Kata Kunci : Tradisi, Aurodan, Masyarakat Cikantrieun

\begin{abstract}
The purpose of this paper is to provide an overview of the aurodan tradition in Cikantrieun Village, Wangunjaya Village, Banjarwangi District, Garut Regency, West Java Province. This is based on the background that Indonesia is a country rich in culture and tradition, each region in Indonesia certainly has its own cultures and traditions, of which there are many Indonesian cultures and traditions documented, some of which are not, it is very possible that there are cultures and traditions of a remote area which is unknown by the public, for this reason, the author tries to convey a religious tradition in a remote area at the southern end of Garut in Kampung Cikantrieun, Wangunjaya Village, Banjarwangi District, Garut Regency, West Java Province. The writing based on the interview and observation describes how the origin of the aurodan tradition, the purpose of the community in carrying out aurodan activities, the benefits of aurodan, the aurodan process and readings in aurodan and their arguments. The aurodan tradition in Cikantrieun village has been existed since decades ago, on its journey of experiencing changes and developments, along with changes and developments in people's thinking in the Cikantrieun village itself, especially religious leaders and community leaders.
\end{abstract}

Keywords: Tradition, Aurodan, Society of Cikantrien

A. PENDahuluan 
menunjukkan identitas jati dirinnya. Eksistensi budaya memberikan warna tersendiri, menjadi bagian yang tidak dapat dipisahkan, membentuk ciri khas, serta menjadi subjek dalam perkembangan manusia menuju peradaban modern. Bangsa yang berdiri dengan kebudayaan yang melimpah, akan mendapatkan nilai tersendiri dari sorotan publik. Karena, bagaimanapun menyatukan perbedaan dalam satu atap kekuasaan tanpa adanya unsur intimidasi merupakan sesuatu yang sangat sulit dicapai kecuali hanya dapat dilakukan oleh bangsa yang besar.

Indonesia merupakan salah satu bangsa yang mampu mewujudkan hal yang hampir mustahil tersebut. bila kita amati kita akan temukan berbagai jenis produk indonesia yang tersebar dari sabang sampai merauke mulai dari adat-istiadat, tradisi, suku, ras, agama, dan bahasa. kesemua unsur tersebut bersatu-padu mengikrarkan dalam satu janji membentuk negara kesatuan. Sehingga dapat dikatakan kekokohan bangsa indonesia bergantung pada unsur budaya yang mengikatnya.

Salah satu produk khazanah budaya yang ada di Indonesia yang mungkin belum begitu diketahui oleh masyarakat secara luas, adalah tradisi aurodan. Dalam artikel ini akan coba kita angkat tradisi aurodan

\footnotetext{
1 Wikipedia, Banjarwangi_Garut, Dalam https://id.wikipedia.org/wiki/Banjarwangi,_Garut, diakses tanggal 10 Oktober 2018.
}

yang ada bagian selatan Garut tepatnya di Kampung Cikantrieun, Desa Wangunjaya, Kecamatan Banjarwangi, Kabupaten Garut, Provinsi Jawa Barat. Tradisi aurodan ini sudah ada sejak puluhan tahun silam, aurodan bagi masyarakat yang berada di Kampung Cikantrieun merupakan kegiatan yang memberi manfaat bagi kehidupan baik diri, keluarga, serta masyarakat bukan sesuatu yang sia-sia.

\section{B. GAMBARAN CIKANTRIEUN}

\section{KAMPUNG}

Kampung Cikantrieun yang berada di Desa Wangunjaya Kecamatan Banjarwangi Kab. Garut merupakan kampung yang masyarakat keseluruhannya beragama Islam. Kampung ini berada dikawasan lereng Gunung Dangdang yang bersebelahan dengan Gunung Pakurante Tasikmalaya. Tepatnya $50 \mathrm{~km}$ dari Garut Kota $^{1}$. Sedangkan jarak tempuh dari kota Bandung ke Garut sekitar 64,2 km², kalau di tempuh dari kota Bandung sekitar 114,2 km untuk sampai ke lokasi, jalur yang di lalui melewati Nagreg, leles, Garut kota, setelah sampai di Garut Kota ngambil jalur selatan Garut yaitu Cisurupan Cikajang.

Kampung Cikantrieun merupakan kampung yang berada di lereng Gunung Dangdang, suasana alam yang sangat

2 Peta \& Rute Perjalanan, dalam http://jaraktempuh.com/jarak-bandung-kegarut.html, diakses taggal 10 Oktober 2018 
dominan dengan nuansa alam pegunungan. Masyarakat hidup dengan suasana kebersamaan, gotong royong serta ikatan kekerabatan yang begitu kuat diantara mereka, senada dengan kekuatan mereka dalam memegang teguh tradisi yang dianggap positif seperti halnya memegang teguh pada tradisi aurodan.

Adapun tradisi-tradisi yang dipandang kurang baik bahkan bertentangan dengan pemahaman keagamaan sedikitdemi sedikit di tinggalkan, seperti halnya tradisi persembahan rujak kelapa ketika mau panen padi, dulu masyarakat terbiasa membuat rujak kelapa lalu di simpan di sawah-sawah yang mau di panen, katanya untuk di persembahkan kepada Sri Nyai (dengan kata lain Dewi Padi), tradisi ini sudah ditinggalkan secara total oleh masyarakat karena ini dipandang kurang baik bahkan bertentangan dengan Agama Islam mengingat mengandung unsur kemusyrikan, namun tradisi dalam pemotongan padi oleh masyarakat tetap di pertahankan karena disitu terdapat unsur saling tolong menolong satu sama lain antar masyarakat.

Tokoh agama dikampung ini berperan penting dalam menjaga stabilitas budaya yang dipandang baik, positif secara nalar dan tidak bertentangan dengan agama. Beban yang dipikulpun oleh tokoh agama ini tidak tanggung-tanggung, seluruh masyarakat menggantungkan semua kegiatan keagamaan dan menjalankan sesuai intruksi darinya. Peran tokoh agama ini istilahnya dari mulai masyarakat yang mau melahirkan sampai masyarakat yang mau meninggal dipastikan meminta do'a dan bimbingan kepadanya.

Dikampung Cikantrieun ada beberapa tokoh agama yang satu sama lain senantiasa bekerja sama dalam mengelola masyarakat, dari sisi pemahaman keagamaan mereka bisa di bilang cukup kalau hanya untuk mengelola satu kampung, mereka senantiasa bersama dalam menjalankan kegiatan-kegiatan keagamaan termasuk dalam menjaga dan melestarikan tradisi aurodan.

\section{ASAL USUL TRADISI \\ AURODAN}

Sebelum lebih jauh rasanya penting untuk menjelaskan apa yang dimaksud dengan tradisi dan apa yang di maksud aurodan.

Tradisi

atau kebiasaan (Latin: traditio,

"diteruskan") adalah sesuatu yang telah dilakukan untuk sejak lama dan menjadi bagian dari kehidupan suatu kelompok masyarakat, biasanya dari suatu negara, kebudayaan, waktu, 
atau agama yang sama ${ }^{3}$ Sedangkan menurut WJS Poerwadaminto, Tradisi adalah segala sesuatu yang menyangkut kehidupan dalam masyarakat yang dilakukan secara terus menerus, seperti adat, budaya, kebiasaan dan juga kepercayaan ${ }^{4}$

Berdasarkan hasil wawancara penulis dengan tokoh agama yang paling sepuh di kampung Cikantrieun yang bernama Ustadz U Sumardi, beliau menjelaskan bahwa kata "Aurodan" itu diambil dari kata wirid atau aurod yang artinya mengemukakan atau menyampaikan, jadi seseorang di katakan sedang berwirid atau sedang beraurod, itu berarti dia sedang mengemukakan atau menyampaikan kepada Allah Swt baik itu berupa penyampaian permintaan ampunan, keberkahan, petunjuk, meminta rejeki, dan lain sebagainya. Selanjutnya Ust. U Sumardi pun menuturkan kenapa dari aurod menjadi "Aurodan" itu berawal dari kata-kata yang berkembang di masyarakat saja seperti halnya baca surat Yasin menjadi istilahnya Yasinan, beliau juga menambahkan disebut "Aurodan" itu karena pelaksanaannya berjama'ah, orang-orang kumpul di satu tempat dan melaksanakan wirid secara berjama'ah serta di pimpin oleh seseorang.

${ }^{3}$ Wikipedia, Tradisi, dalam https://id.wikipedia.org/wiki/Tradisi, diakses tanggal 09 Oktober 2018.

${ }^{4} 16$ Pengertian Tradisi Menurut Para Ahli Terlengkap, dalam https://www.sekolahpendidikan.com /2017/11/16-
Kalimat wirid atau aurod sebagaimana di kemukakan sesepuh kampung Cikantrieun Ust U Sumardi ternyata memiliki beberapa makna diantaranya; mendatangkan, membawa ke, menyebutkan, mengemukakan ${ }^{5}$.

Tradisi aurodan yang berada dikampung Cikantrieun telah ada sejak puluhan tahun yang lalu, namun seiring dengan perkembangan pemikirin masyarakat tradisi aurodan ada perubahan dan perkembangan, yang sebelumnya hanya bacaan-bacaan wirid atau aurod serta bacaan surat Yasin di malam jum'at saja, namun semenjak tahun 1989 ada perubahan yang lumayan signifikan, diantaranya tambahantambahan dalam bacaan wirid atau aurod di tambah lagi bacaan surat yang ada bukan hanya surat Yasin saja, tetapi ditambah dengan surat-surat Al-Qur'an lain seperti surat Al-Kahfi, surat Al-Waqi'ah, surat AlMulk. Selain itu waktunya pun ada tambahan kalau sebelumnya hanya malam Jum'at saja atau hanya seminggu sekali, sekarang jadi seminggu dua kali yaitu malam jum'at dan malam senin.

Ust U Sumardi mengatakan bahwa semenjak beliau ingat tradisi aurodan sudah ada, sedangkan beliau lahir sekitar tahun

pengertian-tradisi-menurut-para-ahli.html, tanggal 09 Oktober 2018

${ }^{5}$ KH. Ali Maksum, KH Zainal Abidin Munawwir, Kamus Almunawwir arab-Indonesia, Pustaka Progressif, Surabaya, 1984. 
1944, jadi menurut ayah beliau, kakeknya merupakan sesepuh lembur dan tokoh agama serta termasuk orang yang suka memimpin aurodan, jadi tradisi aurodan ini turun temurun, namun dalam hal siapa yang jadi sesepuhnya atau pemimpin dalam aurodan, tidak terikat dengan keturunan artinya bisa siapa saja yang penting mampuh dalam memimpin aurodan.

\section{TUJUAN}

\section{PENYELENGGARAAN}

\section{AURODAN}

Hasil wawancara penulis dengan salahsatu tokoh agama yang paling sepuh di kampung Cikantrieun yaitu Ust U Sumardi beliau mengatakan bahwa ada beberapa tujuan dari penyelenggaraan aurodan tersebut, diantaranya adalah

1. Wujud Syukur Pada Nikmat Allah Swt

Sesepuh kampung Cikantrieun mengemukakan bahwa aurodan bagi masyarakat kampung kami merupakan sarana wujud syukur atas semua nikmat dan rizqi yang telah Allah SWT berikan kepada kami. Masyarakat menyadari penuh bahwa syukur kepada Allah SWT merupakan kebutuhan yang tidak boleh ditinggalakan. Setiap hal mulai dari yang terkecil sampai yang terbesar, dari yang tampak sampai yang tidak tampak, kesemuanya adalah wujud kenikmatan yang tidak ternilai.
Dalam praktiknya, sebenarnya wujud syukur itu dapat dilakukan dengan berbagi cara, tidak terbatas hanya dengan mangadakan acara aurodan. Mereka bersandar pada firman Allah Swt bahwa kita harus senantiasa ingat, tatkala Tuhanmu memaklumkan; "Sesungguhnya jika kamu bersyukur, pasti Kami akan menambah (nikmat) kepadamu, dan jika kamu mengingkari (nikmat-Ku), Maka Sesungguhnya azab-Ku sangat pedih"6.

2. Sarana Meminta Ampunan Kepada Allah Swt

Aurodan bagi masyarakat kampung Cikantrieun merupakan sarana untuk meminta ampunan kepada Allah Swt dari segala dosa-dosa dan kesalahan yang pernah di perbuat, baik itu dosa-dosa yang di perbuat antar sesama masyarakat maupun dosa yang diperbuat yang sifatnya hablullah yaitu dosa yang berhubungan kepada Allah Swt, masyarakat sadar bahwa ampunan Allah Swt itu sangat mahal, artinya untuk mendapatkan ampunan tersebut harus dibayar dengan sesuatu yang berharga sehingga diharapkan mampu menjemput ampunan Allah swt itu sendiri. Ust U Sumardi menuturkan diharapkan dengan aurodan yang di lakukan oleh masyarakat secara berjama'ah, Allah Swt berkenan menurunkan ampunannya sehingga dosa dan kesalahan masyarakat kampung

\footnotetext{
${ }^{6}$ Qur'an surat Ibrahiim, ayat 7
} 
Cikantrieun khususnya umumnya dosa muslimin dan muslimat semua diampuni Allah Swt, beliau (ust u sumardi) mengatakan lagi bahwa, sikap yang harus dibangun dalam mengejar ampunan itu "bersegera" kenapa demikian?, karena perintah sang kuasanya begitu, beliau mengutip salah satu ayat al-qur'an;

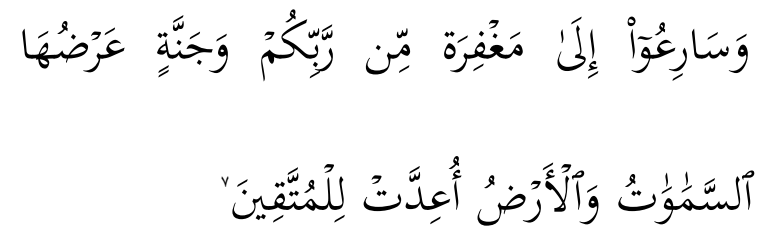

3. Membangun Persaudaraan Sesama Warga

Aurodan merupakan ajang silaturahim sesama masyarakat serta membangun kedekatan diantara mereka, sehingga di harapkan jika sudah terbangun kedekatan yang mendalam tumbuh rasa persaudaraan istilah dalam bahasa sunda "kacai jadi saleuwi kadarat jadi salebah, silih asah, silih asuh, silih asih" artinya masyarakat kampung Cikantrieun seia sekata, satu visi satu tujuan serta tumbuh rasa cinta dan kasih sayang di antara mereka bagaikan tubuh yang satu, apabila ada anggota (tubuh) yang merasa sakit, maka seluruh anggota yang lainnya merasa demam dan tidak bisa tidur. Sifat seperti inilah yang diharapkan tumbuh dan

${ }^{7}$ Qur'an Surat Ali-Imran, ayat 133

Anjuran Saling Mendo'akan, dalam http://pustaka. abatasa.co.id/ pustaka/ detail/doa/ berkembang dari pelaksanaan aurodan tersebut, dengan pelaksanaan aurodan itu pula di harapkan terhindar dari sikap bermusuhan, saling mencaci dan menghina antar sesama warga.

$$
\begin{aligned}
& \text { 4. Aurodan Sarana Saling } \\
& \text { Mendo'akan Sesama Mu'min } \\
& \text { Dalam prakteknya aurodan }
\end{aligned}
$$
dikampung Cikantrieun terkandung di dalamnya do'a yang isinya saling mendo'akan sesama mu'min dan muslim yang masih hidup. Sesama muslim seyogyanya saling mendoakan agar saudara kita senantiasa dalam kebaikan dan keselamatan baik di dunia maupun di akhirat kelak. Orang yang mendoakan saudaranya, mendapat balasan didoakan oleh malaikat. Muhammad Rosulullah saw. bersabda, "Apabila seorang muslim mendoakan kebaikan untuk saudaranya (sesama muslim) yang berjauhan, maka malaikat mendoakan (orang yang berdoa) pula: 'Semoga engkau memperoleh kebaikan juga"8.

\section{Mendo'akan Saudara Yang} Sudah Meninggal

Para jama'ah aurodan secara umum punya keluarga yang sudah meninggal, mereka semua dalam aurodan senantiasa mendo'akan saudaranya yang sudah meninggal agar di terima amal tanggal 08 Oktober 2018. 
baktinya, diampuni segala dosanya dan disimpan di tempat yang layak sebagai mu'min yaitu keni'matan dalam kubur. Mereka berkeyakinan dengan firman Allah yang artinya "Orang-oranng yang beriman, dan yang anak cucu mereka mengikuti mereka dalam keimanan, Kami hubungkan anak cucu mereka dengan mereka, dan Kami tiada mengurangi sedikitpun dari pahala amal mereka"'. bahwa hubungan kekeluargaan itu tetap Allah sambungkan dengan syarat semuanya beriman kepada Allah Swt.

\section{E. MANFAAT KEGIATAN}

\section{AURODAN}

Ada beberapa manfaat yang dirasakan masyarakat dengan adanya kegiatan atau tradisi aurodan tersebut, sebetulnya dalam tujuan penyelenggaraan aurodan itupun sudah termasuk didalamnya manfaat yang dirasakan oleh masyarakat namun selain itu ada manfaat-manfaat lain, diantaranya; ketika ada keperluan yang sifatnya harus dimusyawarahkan dengan masyarakat maka di sela-sela kegiatan aurodan itu bisa di selesaikan artinya bisa di musyawarahkan, baik itu hal-hal yang berkenaan dengan kepemerintahan maupun hal-hal yang berkenaan dengan kegiatan kemasyarakatan itu sendiri.

Selain itu masyarakat merasakan bahwa dengan adanya kegiatan aurodan membantu jika ada keluarga yang sakit dengan do'a-do'a, artinya di ijabkan dalam do'anya untuk kesembuhan keluarga yang sakit tersebut. Selain itu kadang di bantu pula dengan mengumpulkan materi artinya masyarakat bersama-sama mengumpulkan uang atau barang untuk membantu keluarga yang sakit baik itu untuk berobat maupun untuk meringankan beban keluarganya sehar-hari.

Selain itu pula aurodan di rasakan oleh pihak pemerintah terutama oleh pihak desa setempat yaitu Desa Wangunjaya bermanfaat sekali, dimana pemerintah desa merasa terbantu dalam hal membangun dan menciptakan persatuan dan kesatuan dikalangan masyarakat, selain itu desa juga merasa terbantu jika ada hal yang harus di sosialisakan atau di musyawarahkan dengan masyarakat kampung Cikantrieun bisa langsung disampaikan atau di musyawarahkan di sela-sela kegiatan aurodan tersebut bisa sebelum kegiatan atau sesudah kegiatan aurodan.

\section{F. PROSES KEGIATAN} AURODAN

\footnotetext{
${ }^{9}$ Qur'an surat At-Thuur, ayat 21
} 
Supaya memudahkan pembaca, penulis coba melist beberapa hal yang berhubungan dengan kegiatan aurodan yang dilaksanakan di kampung Cikantrieun, diantaranya;

1. Waktu kegiatan

Kegiatan aurodan di kampung Cikantrieun sebelum tahun 1989 di laksanakan setiap malam jum'at selesai sholat maghrib sampai menjelang sholat isya atau bisa di bilang ti tutup kegiatan tersbut dengan melaksanakan sholat isya berjama'ah, namun setelah tahun 1989 waktunya berubah yang tadinya hanya satu malah yaitu malam jum'at saja kerang di tambah dengan malam senin, dan waktunyapun berubah yang tadinya ba'da maghrib sekarang menjadi ba'da isya sampai selesai.

\section{Tempat kegiatan}

Tempat kegiatan aurodan di kampung Cikantrieun ada beberapa perubahan, dimana sebelum tahun 1989 dilaksanakan di masjid atau di mushola dan hanya di laksanakan di malam jum'at saja, namun setelah tahun 1989 seiring dengan perubahan pemikiran masyarakat yang lebih positif tentunya, tempatpun berubah yang tadinya di masjid atau mushola pindah jadi kerumah-rumah warga gantian secara bergiliran, kenapa demikian?. Ust. U
Sumardi mengatakan masyarakat berpandangan bahwa tempat atau rumah yang di pakai untuk kegiatan aurodan penuh dengan keberkahan. Namun seiring dengan waktu pula, sesepuh agama ${ }^{10}$ mengatakan, tidak tau percisnya kapan waktunya, tempatpun berubah yang tadinya di rumahrumah warga pada akhirnya kembali ke masjid dan bertahan sampai sekarang.

3. Kegiatan inti aurodan

Kegiatan inti dalam tradisi aurodan yang ada di kampung Cikantrieun mengalami perubahan setidaknya pernah 3 kali perubahan seiring dengan perkembangan pemikiran keagamaan yang berkembang di masyarakat, diantara kegaiatan yang pernah terlaksana dalam tradisi aurodan adalah sebagai berikut;

a. Kegiatan inti tradisi aurodan sebelum tahun 1989.

Kegiatan aurodan sebelum tahun 1989 berjalan setelah selesai sholat berjama'ah maghrib, para peserta langsung duduk berjejer di masjid membentuk lingkaran dan sesepuh masjid duduk di dekat paimaran atau di dekat mimbar memimpin langsung acara aurodan. Aurodan diawali dengan penyampaian wejangan-wejangan dari sesepuh mengingatkan akan mati, mengingatkan akan kehidupan setelah kehidupan dunia yaitu kehidupan kahirat, mengingatkan akan

\footnotetext{
${ }^{10}$ Ust. U. Sumardi
} 
adanya yaumul ba'ats (hari kebangkitan), yaumul hisab (hari perhitungan amal), yaulul mizan (hari pertimbangan amal) serta mengingatkan hari pembalasan, wejangan ini di sampaikan selama kurang lebih 30 menit. Setelah penyampaian wejangan, sesepuh langsung memimpin membaca aurod yang di awali dengan ta'ud, basmalah, selanjutnya membaca istighfar yaitu memohon ampunan kepada Allah Swt untuk diri, kedua orang tua, keluarga dan sesama saudara seiman dan seislam. Selanjutnya sesepuh aurod membaca sarsilah ${ }^{11}$ yaitu do'a dan fatihah yang di khususkan berkahnya bagi keluarga dan kaum muslimin dan muslimat yang sudah meninggal, sarsilah ini tidak terlalu lama aktunya setelah itu dilanjutkan dengan membaca surat yasin satu kali secara berjama'ah dengan suara nyaring. Selesai membaca surat yasiin sesepuh aurodan langsung memimpin do'a-do'a yang lumayan panjang dan anggota aurodan meng-amiinkannya yang selanjutnya diakhiri dengan bacaan surat al-fatihah bersama-sama selesai itu sampai pada waktu menjelang waktu sholat isya, lalu seseorang diantara anggota aurod berdiri untuk melantunkan adzan isya, selanjutnya sholat isya secara berjama'ah dan selesai.

${ }^{11}$ Sarsilah, sebuah istilah yang dipergunakan di kampung Cikantrieun, untuk menyebut orangorang yang sudah meninggal dan mendo'akannya, b. Kegiatan inti tradisi aurodan setelah tahun 1989.

Kegiatan inti aurodan setelah tahun 1989 berubah dengan kegiatan sebelumnya, dimana perubahannya seiring dengan tempat kegiatan itu sendiri dimana di awalawal setelah tahun 1989 tempatnya di rumah-rumah warga gantian secara bergiliran, kegiatan di rumah ini berjalan sekitar 5 tahunan yang selanjutnya pindah kembali seperti semula yaitu ke masjid, disini coba penulis buat kegiatan yang laksanakan di rumah dan kegiatan yang di laksanakan di masjid:

- Kegiatan inti aurodan setelah tahun 1989 yang di laksanakan di rumah

Acara di mulai selepas warga melaksanakan sholat isya, sebelum acara dimulai, ada waktu berkisar 20 sampai 30 menit untuk menunggu warga yang belum hadir. Biasannya, sambil menunggu warga akan, pribumi menyediakan air minum dan rokok serta makanan-makanan ringan. Setelah diperkirakan warga telah datang semua maka acarapun dimulai, pertama pribumi (yang punya rumah) mempersilahkan kepada sesepuh aurodan untuk memulai acara. Selanjutnya pemimpin acara aurodan memulai dengan menyampaikan ucapan terima kasih kepada hadoroh. 
pribumi (yang punya rumah) atas tempat yang telah di sediakan serta rejeki yang telah di korbankan untuk menjamu warga yang hadir serta mendo'akan yang di khususkan untuk pribumi agar keluarganya di sehatkan, rezekinya diberkahkan dan keluarganya ada dalam lindungan Allah Swt. Dan selanjutnya diteruskan dengan memberi nasihat atau wejangan selama kurang lebih 15 menit yang di sampaikan oleh pimpinan aurod langsung atau oleh siapa saja tokoh agama yang lain yang hadir pada kesempatan itu, selesai wejangan dilanjutkan dengan aurodan yang di pimpin kembali oleh pimpinan aurod, diawali dengan bacaan istighfar 3 kali secara berjama'ah, sholawat 3 kali. Selanjutnnya sarsilah atau istilah lain hadoroh kepada Nabi Muhammad, para keluarga Nabi, sahabat Nabi, para pengikut Nabi, para ulama' lalu membaca surat fatihah bersama. Hadoroh berikutnya untuk para keluarga pribumi yang telah meninggal yang nama-namanya telah ditulis dan di serahkan kepada pemimpin aurodan. Ahli kubur yang ditulis oleh pribumi biasanya keluarga yang sangat dekat, seperti bapak /ibu yang telah meninggal, kakek-nenek, buyut, dan seterusnya, lalu membaca fatihah lagi. Dan terakhir hadoroh untuk seluruh ahli kubur muslimin wal muslimat dan mu'minin wal mu'minat. Selesai sarsilah atau hadoroh, selanjutnya membaca surat yasin satu kali dan dilanjutkan dengan surat lain tergantung pemimpim aurod, namun biasanya selesai surat yasin itu bisa surat al-kahfi atau surat al-waqi'ah atau surat al-mulk, dibaca secara bersama-sama.

Kegiatan terahir ditutup dengan do'a yang diamini oleh seluruh jamaah yang ikut. Setelah selesai berdo'a, sebelum para jama'ah pulang, pribumi atau tuan rumah mengeluarkan hidangan makanan berupa nasi serta lauk-pauknya yang disajikan diatas piring atau ada juga yang menyajikan pakai wadah yang terbuat dari anyaman bambu istilahnya pipiti. Penyajian makanan ini diniatkan untuk sedekah, berbagi antar warga yang nantinya diharapkan lebih mendekatkan diri pribumi khusunya kepada Allah Swt dan menambah eratnya tali persaudaraan diantara sesama warga serta diniatkan pula merupakan wujud rasa syukur kepada Allah Swt.

- Kegiatan inti tradisi aurodan setelah tahun 1989 yang di laksanakan di mesjid

Seiring dengan berjalannya waktu setelah sekitar 4 tahun berjalan, tempat pelaksaaan kegiatan aurodan di rumahrumah warga pada akhirnya pindah kembali ke masjid, dimana waktu pelaksanaannya sama seperti di rumah setelah selesai sholat isya.

Setelah selesai sholat berjama'ah Isya para jama'ah yang sudah hadir di masjid langsung duduk berjejer membentuk 
lingkaran sambil mereka menunggu jama'ah yang lain terutama ibu-ibu karena tidak ikut sholat Isya berjama'ah menunggu ini kurang lebih 20 menit sampai 30 menit, setelah dipandang cukup kehadiran para jama'ah baru sesepuh masjid duduk di dekat paimaran atau di dekat mimbar dan langsung memimpin langsung acara aurodan. Aurodan diawali dengan penyampaian wejangan-wejangan dari sesepuh mengingatkan akan mati, mengingatkan akan kehidupan setelah kehidupan dunia yaitu kehidupan kahirat, mengingatkan akan adanya yaumul ba'ats (hari kebangkitan), yaumul hisab (hari perhitungan amal), yaulul mizan (hari pertimbangan amal) serta mengingatkan hari pembalasan, wejangan ini di sampaikan selama kurang lebih 30 menit. Setelah penyampaian wejangan, sesepuh langsung memimpin membaca aurod yang di awali dengan basmalah serta ta'ud (meminta perlingdungan dari godaan setan), selanjutnya membaca istighfar $3 \mathrm{kali}$ yaitu memohon ampunan kepada Allah Swt untuk diri, kedua orang tua, keluarga, dan untuk kaum muslimin dan muslimat, dilanjutkan sholawat kepada Nabi sebanyak 3 kali.

Selanjutnya sesepuh aurod membaca sarsilah atau istilah lain hadoroh kepada Nabi Muhammad Saw, para keluarga Nabi, sahabat Nabi, para pengikut Nabi, para ulama' serta muslimin dan muslimat yang sudah meninggal lalu membaca surat fatihah bersama, sarsilah atau hadoroh ini tidak terlalu lama waktunya setelah itu dilanjutkan dengan membaca surat yasin satu kali dilanjutkan dengan surat lain tergantung pemimpim aurod, namun biasanya selesai surat yasin itu bisa surat alkahfi atau surat al-waqi'ah atau surat almulk, dibaca secara bersama-sama (berjama'ah) dengan suara nyaring. Selesai membaca surat yasiin dan surat yang lainnya sesepuh aurodan langsung memimpin do'ado'a yang lumayan panjang dan anggota aurodan meng-aminkannya yang selanjutnya diakhiri dengan bacaan surat alfatihah bersama-sama.

4. Peserta kegiatan aurodan

Peserta kegiatan aurodan di kampung Cikantrieun di ikuti seluruh masyarakat yang berkenan baik laki-laki maupun perempuan, tidak di batasi dengan usia baik muda maupun tua bahkan anakanakpun kadang pada mengikuti, yang uniknya lagi kadang ada peserta dari daerah lain bisa itu kenalan-kenalan masyarakat maupun kenalan para kyai atau tokoh agama disitu, mereka semua yang datang dari daerah lain ingin mendapatkan barokah, mereka yang datang berkeyakinan dengan mengikuti kegiatan aurodan tersebut akan mendapatkan keberkahan dari Allah Swt, beban-beban akan di ringankan, yang lagi sakit akan di sembuhkan dan yang sedang dilanda kesulitan akan di mudahkan. 


\section{G. BACAAN-BACAAN DALAM \\ AURODAN SERTA DALIL- DALILNYA}

Diantara rangkaian kegiatan aurodan yang di gelar dikampung Cikantrieun ada beberapa bacaan, baik itu berupa do'a-do'a ataupun bacaan surat-surat alqur'an, diantara bacaan serta dalilnya;

1. Ta'awud

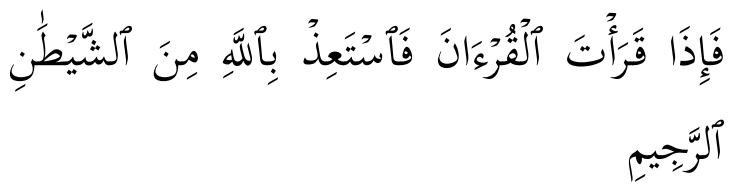

Artinya : apabila kamu membaca Al Quran hendaklah kaти meminta perlindungan kepada Allah dari syaitan yang terkutuk.(Qs.16:98)

2. Basmalah

Dari Abu Hurairah radhiyallahu 'anhu, Rasulullah shallallahu 'alaihi wa sallam bersabda,

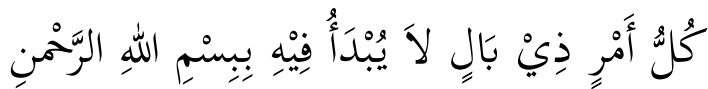

$$
\begin{aligned}
& \text { الرَّحِيْمِ فَهُهُ أَبْتَرُ }
\end{aligned}
$$

"Setiap perkara penting yang tidak dimulai dengan 'bismillahirrahmanir rahiim', amalan tersebut terputus berkahnya." (HR. Al-Khatib dalam Al-Jami', dari jalur ArRahawai dalam Al-Arba'in, As-Subki dalam tabaqathnya) ${ }^{12}$.

Dalam redaksi lain,

$$
\text { كل أمر ذي بال لا يبدأ فيه ببسم الله الرحمن }
$$

\footnotetext{
${ }^{12}$ Muhammad Abduh Tuasikal, MSc.Mulailah dengan bismilah, dalam https://rumaysho.com/14810-mulailah-denganbismillah.html, diakses tanggal 08 Oktober 2018.
}

"Setiap perkara penting yang tidak diawali dengan Bismillahirrahmanirrahim, maka dia akan terputus." (HR. Ibnu Hibban dan selainnya. Ibnu Shalah menyatakan hadits ini hasan $)^{13}$

3. Istighfar

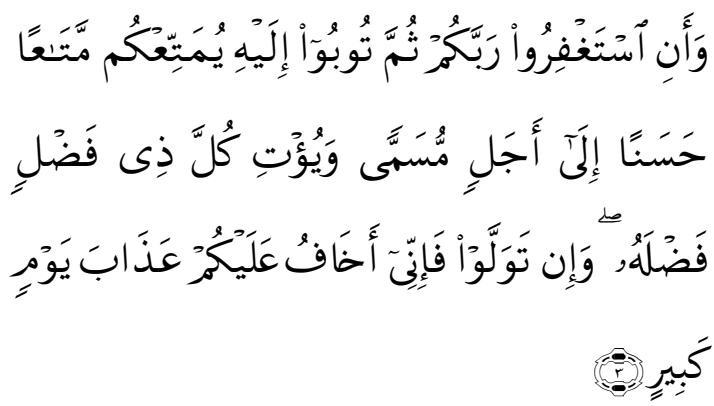

Artinya : dan hendaklah kamu meminta ampun kepada Tuhanmu dan bertaubat kepada-Nya. (jika kamu mengerjakan yang demikian), niscaya Dia akan memberi kenikmatan yang baik (terus menerus) kepadamu sampai kepada waktu yang telah ditentukan dan Dia akan memberikan kepada tiap-tiap orang yang mempunyai keutamaan (balasan) keutamaannya. jika kamu berpaling, Maka Sesungguhnya aku takut kamu akan ditimpa siksa hari kiamat.(Qs.11:3)

Dalam hadits Qudsi, bahwa Allah (berfirman:

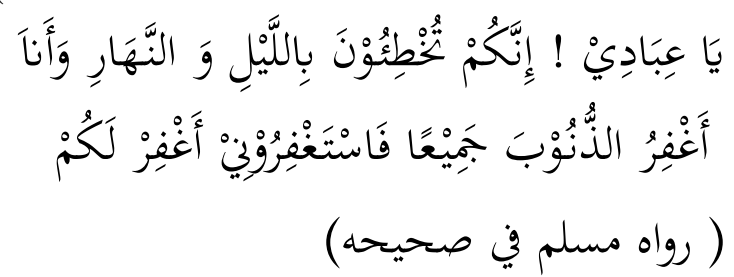

"Wahai para hamba-Ku! Sesungguhnya kalian berbuat salah di malam dan siang hari. Dan Aku mengampuni dosa-dosa

13 VOA Islam, Awali Aktifitas Baik Kita dengan Basmalah, dalam http://www.voaislam.com/read /aqidah/2015/11/02/40327/awaliaktifitas-baik-kita-dengan-basmalah/\#sthash. wDbvVAQj.dpbs, diakses 08 Oktober 2018. 
semuanya. Maka mintalah ampun kepadaKu, Aku akan (HR. Muslim)"14.

4. Surat Al-fatihah

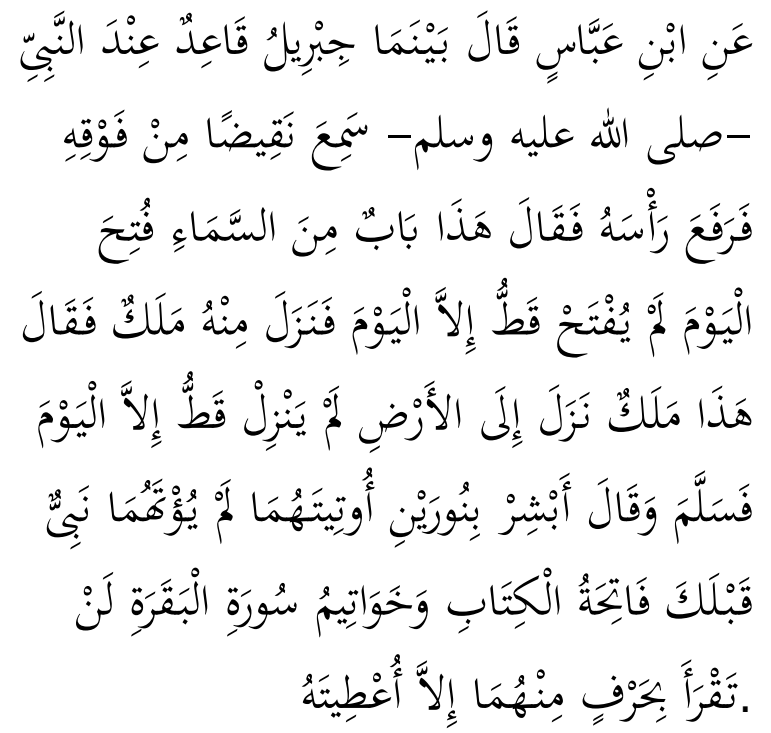

"Dari Ibnu 'Abbas -radhiyallahu 'anhubeliau berkata: saat Jibril duduk disamping Nabi -shallallahu 'alaihi wa sallammendengar suara[3] dari atasnya maka dia menengadahkan kepalanya dan berkata: suara- ini adalah salah satu pintu langit yang dibuka hari ini, belum pernah dibuka kecuali hari ini. Maka turunlah seorang malaikat, dia berkata: ini adalah seorang malaikat yang turun kebumi, dimana dia sama sekali belum pernah kebumi kecuali hari ini, kemudian malaikat itu mengucap salam dan berkata: berilah dengan kabar gembira dengan dua cahaya ini yang telah diberikan padamu, yang tidak pernah

${ }^{14}$ Ghofar 1, Ayat Hadist Dalil Istighfar Dan Keutamaannya, dalam https://ghofar1.blogspot.com /2016/06/ ayat-hadist-dalil-istighfar-dan.html, diakses tanggal 08 Oktober 2018

${ }^{15}$ Buletin Jum'at Al-Atsariyyah, Keutamaan Surat Al-Fatihah, dalam https://qurandansunnah. Wordpress .com /2010/02/19/ keutamaan-surat-alfatihah/, diakses tanggal 08 Oktober 2018 diberikan kepada nabi sebelummu, surat alFatihah dan akhir ayat al-Baqarah, tidaklah engkau membacanya kecuali akan diberikan.” (H.R. Muslim)

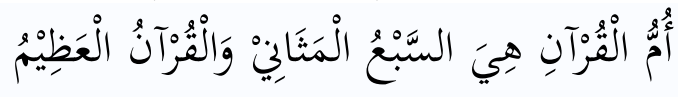

“Ummul Qur'an (yakni, Al-Fatihah) adalah tujuh ayat yang berulang-ulang, dan AlQur'an Al-Azhim “. (HR. Al-Bukhoriy $)^{15}$

5. Surat Al-ikhlas

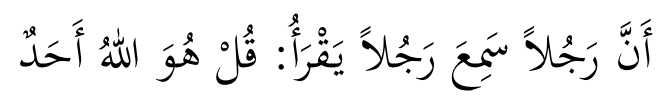

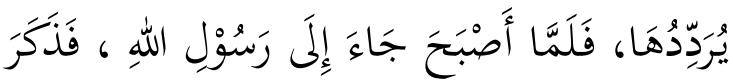

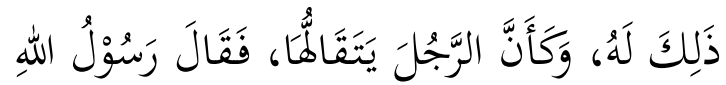

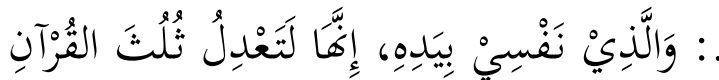

"Sesungguhnya seseorang mendengar

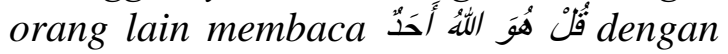
mengulang-ulangnya, maka tatkala pagi harinya, ia mendatangi Rasulullah $n$ dan menceritakan hal itu kepadanya, dan seolah-olah orang itu menganggap remeh surat itu, maka bersabdalah Rasulullah Shallallahu alaihi wa sallam : "Demi Dzat yang jiwaku berada di tanganNya, sesungguhnya surat itu sebanding dengan sepertiga al Qur 'an".(HR. Bukhari) ${ }^{16}$

6. Surat Al-Falaq \& An-Nas

Tidak ada surat yang menyerupainya-yang digunakan untuk beristi'adzah (minta perlindungan)_-di dalam Taurat, Injil, bahkan al-Qur'an. Al-Imam Muslim meriwayatkan dalam Shahih-nya, dari

\footnotetext{
${ }^{16}$ Abu Abdillah Arief B. bin Usman Rozal, Keutamaan Surat Al-Ikhlash, Dalam https://almanhaj.or.id /2613-hadits-hadits-yangmenerangkan-keutamaan-surat-al-ikhlash. html, diakses tanggal 08 Oktober 2018.
} 
'Uqbah bin 'Amir radhiyallahu 'anhu, Nabi shalallahu 'alaihi wassalam bersabda,

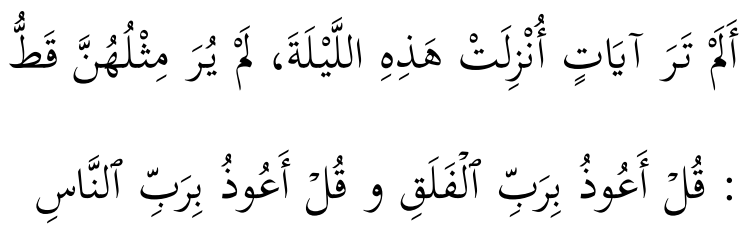

"Tidakkah kamu melihat ayat-ayat yang diturunkan pada malam ini? Tidak ada yang semisal dengannya sama sekali. Ayatayat tersebut adalah surat Qul a'udzu birabbil falaq dan Qul a'udzu birabbin nas. " 17

\section{Surat Yasiin}

Dari Anas bin Malik radhiyallahu 'anhu, ia berkata bahwa Nabi shallallahu 'alaihi wa sallam bersabda,

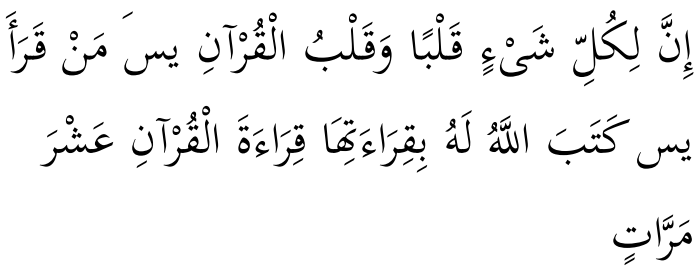

"Segala sesuatu memiliki jantung. Jantungnya Al-Qur'an adalah surah Yasin. Siapa yang membaca surah Yasin, maka Allah akan mencatat baginya seperti membaca Al-Qur'an sepuluh kali." (HR. Tirmidzi $^{18}$

8. Surat Al-Kahfi

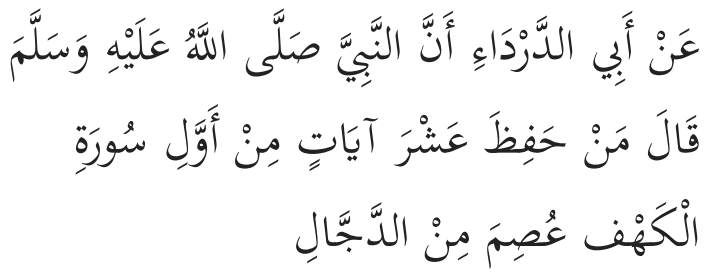

Dari Abu Darda` bahwa Nabi shallallahu 'alaihi wasallam bersabda: "Siapa yang menghafal sepuluh ayat dari awal surah Al Kahfi, maka ia akan terpelihara dari (kejahatan) Dajjall. (HR Muslim) ${ }^{19}$

9. Surat Al-Waqi'ah

Adapun keutamaan surat al-waqiah ada yg shahih, namun banyak juga yang dha'if. Yang shahih datang hanya dalam 1 makna, yaitu

$$
\begin{aligned}
& \text { شيبتني هود، والواقعة، والمرسلات، وعم } \\
& \text { يتساءلون، وإذا الشمس كورت } \\
& \text { (سنن الترمذي) ( - (سن) }
\end{aligned}
$$

Aku beruban (karena memikirkan kandungan) surah Huud, Al-Waqi'ah, AnNaba', dan At-Takwir. [Sunan Tirmidzi: dihasankan oleh Syaikh al-Albânî] Adapun hadits selain makna di atas, maka tdk lepas dari kelemahan.

10. Surat Al-Mulk

$$
\begin{aligned}
& \text { عن عبدِ اللهِ بنِ مسعودٍٍ قال: لامن قرأ كَتَبَارَكَ }
\end{aligned}
$$

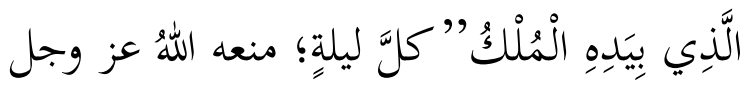

$$
\begin{aligned}
& \text { بها من عذابِ القبر، وكنا في عهدِ رسولِ اللِِ } \\
& \text { نسميها المانعةَ، وإها في كتابِ اللهِ عز وجل }
\end{aligned}
$$

https://rumaysho.com/16381-keutamaan-suratyasin.html, diakses tanggal 08 Oktober 2018.

${ }^{19}$ Pusat Kajian Hadits HQA (Hamalatul Qur'an wal Atsar) Solo, Hadits-hadits Shahih Seputar Surat dan Ayat Tertentu, dalam https://anamuslim.org/hadits-hadits-shahih-seputarsurat-dan-ayat-tertentu/, diakses tanggal 08 Oktober 2018. 


$$
\begin{aligned}
& \text { سورةٌ من قرأ بها في ليلةِ فقد أكثر وأطابه } \\
& \text { (حسن). صحيح الترغيب برقم }
\end{aligned}
$$

Artinya: Barang siapa yang membaca surat Tabarak setiap malam, Allah akan melindunginya dari siksa kubur, dan kami pada masa Rasulullah -shallallahu 'alaihi wa sallam- menamakannya "Surat Pelindung/Penghalang”. Dan ia adalh termasuk surat dalam al Qur'an yang bagi siapa saja yang membacanya setiap malam, maka ia melakukan amalan baik dan banyak”. (Hasan, HR . Nasa'i dalam "Sunan Kubra" 10547, dan dalam "Amanl Yaum wal Lailah" 711, dan Abu Thahir al Mukhlis dalam "Al Mukhlashiyat" 228)

\section{H. KESIMPULAN}

Tradisi aurodan adalah kegiatan keagamaan yang dilestarikan dikampung Cikantrieun, dan mungkin dibeberapa daerah lainnya juga ada yang serupa. Aurodan dikampung Cikantrieun telah ada sejak puluhan tahun yang lalu, tradisi ini melekat dimasyarakat karena memiliki nilai religius, nilai historis yang tinggi dan mengandung manfaat yang besar. Setiap warga yang menjalankan kegiatan ini memiliki tujuan yang sama yaitu sebagai wujud syukur nikmat kepada Allah Swt, sarana meminta ampunan kepada Allah Swt, membangun persaudaraan sesame warga, sarana saling mendo'akan sesama mu'min yang masih hidup serta mendo'akan saudara yang sudah meninggal. Acara ini dilakukan dengan serangkaian acara yang dipimpin oleh sesepuh aurod, sebetulnya para jama'ah tidak ada paksaan untuk mengikuti acara ini. Istilah aurodan sebetulnya bukanlah sebuah tradisi Islam karena pada zaman Rosulullah tidak ada acara aurodan. Namun, jika diperhatikan beberapa rangkaian kegiatan aurodan itu sendiri secara substansi tidak ada yang bertentangan.

Sebagai khasanah tradisi bangsa, acara aurodan patut untuk dilestarikan karena menjaga tradisi bangsa berarti juga menjaga stabilitas kehidupan bangsa. Menolak acara aurodan tidak harus dilakukan dengan cara memberikan serangan secara sporadis kepada masyarakat yang menjalankannya karena itu jelas merusak tatanan persatuan bangsa, tidak perlu adanya hujatan-hujatan untuk menolak acara ini. Meluruskan bukan berarti mengintimidasi. Setiap warga negara memperoleh perlindungan untuk menjalankan apa yang diyakininya.

\section{DAFTAR PUSTAKA}

\section{Al-Qur'anul Karim}

Ust. U Sumardi. Tradisi Aurodan. Wawancara oleh Saepurohman. 4-5 Oktober 2018

Wikipedia, Banjarwangi_Garut, Dalam https://id.wikipedia.org/wiki/B anjarwangi,_Garut, diakses taggal 10 Oktober 2018.

Peta \& Rute Perjalanan, dalam http://jaraktempuh.com/jarakbandung-ke-garut.html, diakses taggal 10 Oktober 2018 
Wikipedia, d wikipedia org/wiki/Tr adisi, diakses tanggal 09 Oktober 2018.

16 Pengertian Tradisi Menurut Para Ahli Terlengkap, dalam https://www.sekolahpendidikan .com /2017/11/16-pengertiantradisi-menurut-para-ahli.html, tanggal 09 Oktober 2018

KH. Ali Maksum, KH Zainal Abidin Munawwir, Kamus Almunawwir arab-Indonesia, Pustaka Progressif, Surabaya, 1984.

Anjuran Saling Mendo'akan, dalam http://pustaka. abatasa.co.id/ pustaka/ detail/doa/ allsub/ 935/ anjuran-saling-

mendoakan.html, diakses tanggal 08 Oktober 2018.

Muhammad Abduh Tuasikal, MSc.Mulailah dengan bismilah, dalam

https://rumaysho.com/14810-

mulailah-dengan-

bismillah.html, diakses tanggal 08 Oktober 2018.

VOA Islam, Awali Aktifitas Baik Kita dengan Basmalah, dalam http://www.voa-islam.com/read /aqidah/2015/11/02/40327/awal i-aktifitas-baik-kita-denganbasmalah/\#sthash.wDbvVAQj. dpbs, diakses 08 Oktober 2018.

Ghofar 1, Ayat Hadist Dalil Istighfar Dan Keutamaannya, dalam https://ghofar1.blogspot.com/2 016/06/ayat-hadist-dalilistighfar-dan.html, diakses tanggal 08 Oktober 2018

Buletin Jum'at Al-Atsariyyah, Keutamaan Surat Al-Fatihah, dalam https://qurandansunnah. wordpress.com/2010/02/19/ keutamaan-surat-al-fatihah/, diakses tanggal 08 Oktober 2018

Abu Abdillah Arief B. bin Usman Rozal, Keutamaan Surat Al-Ikhlash,
Dalam

https://almanhaj.or.id/2613-

hadits-hadits-yangmenerangkan-keutamaan-suratal-ikhlash. html, diakses tanggal 08 Oktober 2018.

Majalah Muslimah Qonitah, Keagungan Surat Al-Falaq dan An-Nas, dalam

https://qonitah.com/keagungansurat-al-falaq-dan-an-nas-almuawwidazatain-bagian-1/, diakses tanggal 08 Oktober 2018.

Muhammad Abduh Tuasikal, MSc. Keutamaan Surat Yasin, dalam https://rumaysho.com/16381keutamaan-surat-yasin.html, diakses tanggal 08 Oktober 2018.

Pusat Kajian Hadits HQA (Hamalatul Qur'an wal Atsar) Solo, Haditshadits Shahih Seputar Surat dan Ayat Tertentu, dalam https://anamuslim.org/haditshadits-shahih-seputar-suratdan-ayat-tertentu/, diakses tanggal 08 Oktober 2018. 